\title{
Evolução da planície costeira das Praias do Sul e do Leste - Ilha Grande/RJ: implicações sobre a presença humana pre-histórica e contribuições para a reconstrução paleoambiental holocênica \\ Evolution of Sul and Leste Beaches coastal plain-Ilha Grande/RJ(Brazil): implications on pre-historical human settlement and contributions for holocene paleoenvironmental reconstruction
}

\section{Rafael Cuellar de Oliveira e Silva ${ }^{\text {ab }}$, Gilberto Tavares de Macedo Dias ${ }^{\text {ac }}$}

aPrograma de Pós-Graduação em Dinâmica dos Oceanos e da Terra, Laboratório de Geologia Marinha (LAGEMAR), Departamento de Geologia, Instituto de Geociências, Universidade Federal Fluminense (UFF)

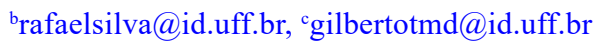

\begin{abstract}
Resumo
A área de estudo deste trabalho possui ambientes lagunares bem preservados e sítios arqueológicos com idade de 3.000 anos AP. Dados altimétricos e análises de imagens aéreas permitiram a identificação de duas barreiras arenosas. Considerando a variação holocênica do nível relativo do mar, concluiu-se que a barreira interna possui idade pleistocênica. A externa, que inclui as praias atuais, formou-se durante a transgressão holocênica. Antigas desembocaduras fluvio-lagunares holocênicas apresentam-se nos extremos ocidental da Praia do Sul e oriental da Praia do Leste. O estabelecimento de um sítio arqueológico na barreira holocênica pode estar relacionado à antiga desembocadura na Praia do Leste. Neste caso, é possível que este sítio seja mais antigo do que o sítio do Ilhote, o qual pode ter sido ocupado somente a partir de 3.000 anos AP porque o nível do mar em rebaixamento teria facilitado o acesso. A sedimentação das lagoas tem sido investigada e apresentam-se resultados preliminares da análise de duas sondagens a percussão realizadas na Lagoa do Sul. A base do testemunho LS01 foi datada por ${ }^{14} \mathrm{C}$ em $2.477-2.138$ anos cal AP, a $116 \mathrm{~cm}$, e do testemunho LS02, em $5.309-4.986$ anos cal AP, a $136 \mathrm{~cm}$. Os sedimentos lagunares são formados por lama orgânica de origem mista a terrestre, com camadas ricas em conchas e lentes arenosas de quartzo, interpretadas como resultado de episódios de enxurradas típicas da região, com alta pluviosidade. A sedimentação e a razão C:N indicam estabilidade ambiental com clima úmido nos últimos $~ 5.000$ anos AP. Entre $1.394-1.174$ e $795-481$ anos cal AP ocorreu o intervalo mais úmido, com: (i) deposição concentrada de conchas e (ii) maior aporte de terrígenos. Maior quantidade de lentes arenosas foi depositada a partir de 3.066-2.647 anos cal AP, sugerindo maior frequência de chuvas intensas desde então.
\end{abstract}

Palavras-chaves: evolução geomorfológica; planície costeira; Holoceno; ocupação humana; reconstrução paleoambiental.

\begin{abstract}
The study area of this research includes preserved lagoonal environments and archaeological sites dated at 3,000 years BP. Aerial imagery analysis and altimetry data allowed the identification of two sandy barriers. Considering Holocene variations of relative sea level, it was concluded that the internal barrier has a Pleistocene age. The external barrier was formed during the Holocene transgression and includes modern beaches. Ancient Holocene river-lagoon mouths are set in the western extreme of Praia do Sul beach and eastearn of Praia do Leste beach. The establishment of an archaeological site in the Holocene barrier can be related to the paleomouth at Praia do Leste beach. Therefore, it is possible that this site is older than the site of Ilhote, which may had been occupied only from 3,000 years BP because the sea level lowering would have facilitated access. Sedimentation of the lagoons has been investigated and preliminary results are presented from analysis carried out on two cores recovered through percussion in Lagoa do Sul lagoon. The base of core LS01 was dated by ${ }^{14} \mathrm{C}$ at $2,477-2,138$ years cal BP, at $116 \mathrm{~cm}$, and core LS02, at 5,309-4,986 years cal BP, at $136 \mathrm{~cm}$. Lagoon sediments are constituted of organic mud of mixed to terrestrial origin with rich layers of shells and quartz sandy lenses, interpreted as result of typical flooding episodes in the region, with high rainfall levels. Sedimentation and C:N ratio indicate environmental stability with wet weather during the last ca. 5,000 years BP. Between 1,394 1,174 and $795-481$ years cal BP was the wettest range, with (i) concentrated deposition of shells and (ii) higher contribution of terrigenous material. Greater amount of sandy lenses was deposited from $3,066-2,647$ years BP, suggesting higher frequency of intense rainfall events.
\end{abstract}

Keywords: geomorphological evolution; coastal plain; Holocene; human settlement; paleoenvironmental reconstruction. 


\section{Introdução}

Esta pesquisa envolve estudos multidisciplinares a respeito da evolução da planície costeira das Praias do Sul e do Leste, na Ilha Grande (Angra dos Reis, RJ). Foram utilizados dados de sensoriamento remoto e medições altimétricas para analisar a morfologia do relevo. Paralelamente, apresentam-se resultados preliminares da análise da estratigrafia de dois testemunhos coletados na Lagoa do Sul, quanto à sedimentação, razão $\mathrm{C}: \mathrm{N}$, datação ao ${ }^{14} \mathrm{C}$ por $\mathrm{AMS}$ e identificação de microfósseis.

Amador (1988) descreveu distintas unidades sedimentares da planície costeira, dentre as quais um sistema de barreira interna e outro de barreira externa. Sua interpretação sobre a gênese destes depósitos foi fundamentada nas curvas de variação do nível do mar propostas por Suguio et al. (1985) e Martin et al. (1986, 1987), relacionando a formação da barreira interna ao máximo transgressivo holocênico, entre 6.000 e 5.000 anos AP, e a formação da barreira externa às oscilações relativas do nível do mar entre 4.500 e 3.000 anos AP.

Neste estudo, fotografias aéreas estereoscópicas, dados SRTM e medições geodésicas foram utilizadas. Propõese uma interpretação da evolução geomorfológica à luz das curvas de variação relativa do nível do mar apresentadas por Angulo \& Lessa (1997) e Angulo et al. (2006), o que leva a formação da barreira interna a idades pleistocênicas e a formação da barreira externa como consequência do máximo transgressivo holocênico. Apresenta-se também uma versão atualizada do mapa geomorfológico publicado por Amador (1988).

Registros arqueológicos, apresentados por Tenório (2000, 2003, 2006) e Tenório et al. (2008), datam a presença humana na região desde $\sim 3.000$ anos AP por comunidades de pescadores-coletores-caçadores, identificados como "fabricantes de machado da Ilha Grande". Tais publicações relacionam a dinâmica de ocupação pré-histórica também às variações relativas do nível do mar defendidas por Suguio et al. (1985) e Martin et al. (1986, 1987). Tendo em vista a reinterpretação sobre a evolução da planície costeira, este trabalho aponta questionamentos e conjecturas a respeito da idade e da dinâmica de ocupação humana na região.

\section{2. Área de estudo}

A Ilha Grande situa-se no litoral sudoeste do estado do Rio de Janeiro, no município de Angra dos Reis (figura 1), possui $193 \mathrm{~km}^{2}$ de área e altitude máxima em torno de 1.000 metros. Está inserida no Terreno Oriental da Faixa Ribeira Central e sua litologia é composta principalmente por granitos e charnockitos, e também por ortognaisses e diques de diabásio (Eirado et al. 2006).

A planície costeira das Praias do Sul e do Leste, localizada na face sudoeste da Ilha Grande, possui cerca de $5 \mathrm{~km}^{2}$ de área, onde se encontram as lagoas do Sul e do Leste, respectivamente à retaguarda das duas praias de mesmo nome. Ambas as lagoas se comunicam com o mar através de um canal com 1,4 km de comprimento e 20 metros de largura média, que desemboca no canto ocidental da Praia do Leste, adjacente a uma pequena península, conhecida como Ilhote do Leste (figura 2). Os ecossistemas existentes na região encontram-se preservados, protegidos desde 1981 pela Reserva Biológica Estadual da Praia do Sul.

O clima da Ilha Grande é tropical, quente e úmido. No verão, a temperatura pode chegar a $39^{\circ} \mathrm{C}$ e no inverno pode alcançar valores mínimos inferiores a $10^{\circ} \mathrm{C}$ (Salgado \& Vasquez 2009). Chuvas intensas, mais frequentes no verão, são as características climáticas mais marcantes. A bacia hidrográfica onde está inserida apresenta um dos maiores índices pluviométricos do país, com precipitação geralmente superior a 2.000 $\mathrm{mm} /$ ano (Salgado et al. 2007).

\subsection{Contexto arqueológico}

Segundo Tenório (2003), foram contabilizados 56 sítios arqueológicos em toda a Ilha Grande: 47 oficinas líticas, 7 sítios "sobre dunas", um sambaqui a "meiaencosta" e um "abrigo sob rocha". As oficinas líticas localizam-se nos costões rochosos de todas as praias que dispõem de cursos de água doce, predominando nas praias voltadas ao mar aberto. Constituem-se de conjuntos de amoladores-polidores fixos, rochas com sulcos resultantes da fabricação de artefatos líticos polidos (Tenório et al. 2008).

$\mathrm{Na}$ área deste estudo, Tenório (2003) descreveu os seguintes sítios arqueológicos: (i) Toca do Índio ("abrigo sob rocha"); (ii) Sítio da Estrada ("sobre duna"); (iii) Sítio do Ilhote do Leste (sambaqui a "meia-encosta"); (iv) Sítio da Ponta do Leste ("sobre duna"); e (v) três oficinas líticas (figura 2).

A Toca do Índio está às margens da Lagoa do Sul, próxima a uma antiga trilha que liga a região à praia da Longa, na face NO da ilha. O Sítio da Estrada localizase na Praia do Sul, a cerca de 1.000 metros do Ilhote do Leste. Ambos encontram-se completamente destruídos, oferecendo poucas informações, apenas uma camada de $50 \mathrm{~cm}$ de material contendo conchas do bivalve Phacoides pectinatus (Gmelin 1791) e lascas de quartzo (Tenório 2003). Não há datações disponíveis sobre estes sítios.

O sambaqui no Ilhote do Leste é o sítio onde foi encontrada a maior quantidade de material arqueológico, conforme Tenório (2003, 2006), indicando que o ilhote foi o principal local de fixação, com acúmulo de quase três metros de restos alimentares, artefatos e sepultamentos (Tenório et al. 2008). As datações mostram que o sambaqui manteve-se ativo por algumas centenas de anos, a partir de $3.060 \pm 40$ anos AP (3.360 3.160 anos cal AP). A dieta alimentar era diversificada, incluindo mamíferos e grandes peixes, até mesmo tubarões, que sugerem especial habilidade para caça e pesca (Tenório 2003, 2006). Segundo Tenório et al. (2008), há maior acúmulo de material arqueológico na área central. Lâminas de machado foram encontradas sempre associadas a sepultamentos, comprovando a

1 Nome científico atualizado conforme Bouchet \& Taylor 2015. 


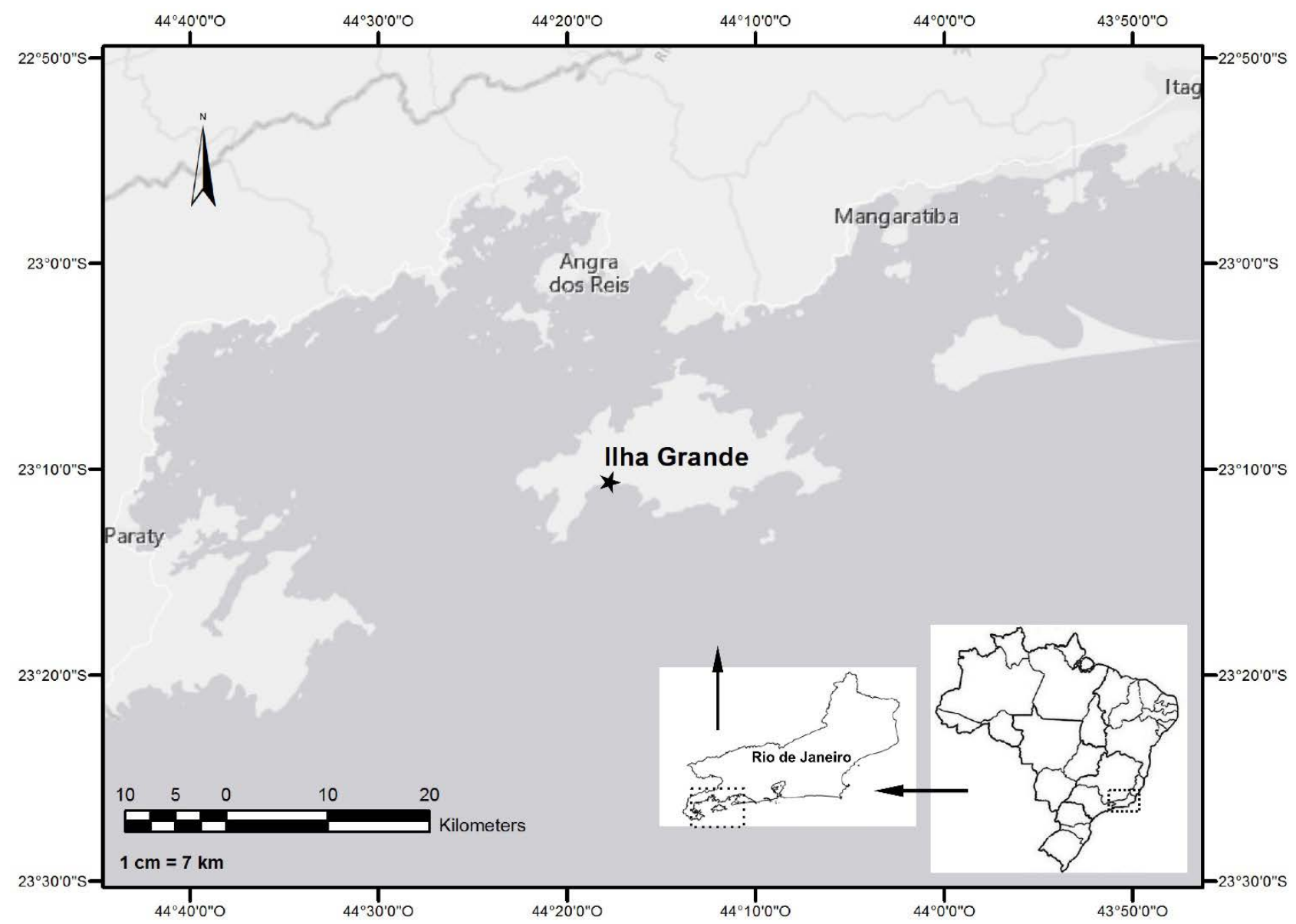

Figura 1: Localização da área de estudo (assinalada pela estrela).

relação dos habitantes com os amoladores-polidores fixos. Foram encontrados 33 esqueletos, em 30 enterramentos, a maioria de indivíduos com idade superior a 30 anos. A grande quantidade de diferentes tipos de artefatos encontrados indica intenso contato com outros grupos costeiros. Foram identificados dois platôs de assentamento, um a 13 metros e o outro a 20 metros acima do nível do mar atual, sendo que o primeiro, segundo Tenório $(2003,2006)$, teria sido "abandonado com a subida do nível do mar", há $2.830 \pm 50$ anos $\mathrm{AP}(3.070-2.800$ anos cal AP). O domínio do sítio foi relacionado ao uso de diversas fogueiras, mantidas acesas por dezenas de anos nos mesmos locais (Tenório 2003, 2006).

O Sítio da Ponta do Leste encontra-se a 1.500 metros de distância do ilhote, sobre a barreira externa, a cerca de 3 metros acima do nível do mar atual, ao lado do leito seco de um córrego. De acordo com Tenório et al. (2008), na parte preservada do sítio foi encontrado um enterramento em ótimo estado de preservação, a profundidade de $150 \mathrm{~cm}$. O esqueleto corresponde a um indivíduo do sexo masculino, com mais de 35 anos de idade e 1,60 m de altura, menos desenvolvido do que os demais encontrados no Sítio do Ilhote, mas apresentando patologias ósseas similares. Além do enterramento, o sítio possui apenas $30 \mathrm{~cm}$ de espessura de uma camada escura, contendo finas lentes de fogueiras, ossos de fauna, valvas de moluscos e lascas de quartzo. Datação obtida em amostra de carvão resultou em $2.880 \pm 40$ anos AP (3.140 - 2.880 anos cal AP) (Tenório et al. 2008).

As oficinas líticas localizam-se ao lado dos sítios do Ilhote do Leste e da Ponta do Leste, onde está a maior concentração de amoladores-polidores fixos de toda a Ilha Grande (Tenório 2003). Os amoladores estão sempre adjacentes às barras de córregos, pois os objetos líticos eram produzidos a partir do processo de abrasão, pelo atrito da peça com outra rocha, agregando-se areia e água. Segundo Tenório (2003), a presença de amoladores no costão rochoso ao redor de quase todo o Ilhote do Leste indica que estes foram produzidos em período de nível relativo do mar mais baixo que o atual, quando a barra do canal estava mais adiante.

\section{Metodologia}

\subsection{Sensoriamento remoto}

Foram utilizados dados SRTM (Shuttle Radar Topography Mission) com resolução de $30 \mathrm{~m}$, obtidos em http://earthexplorer.usgs.gov/, e fotografias aéreas estereoscópicas de 1991.

\subsection{Altimetria}

Para se obter um controle altimétrico das análises por sensoriamento remoto e da estratigrafia dos testemunhos com relação ao nível médio do mar atual (NMM), foi realizado um levantamento geodésico no 


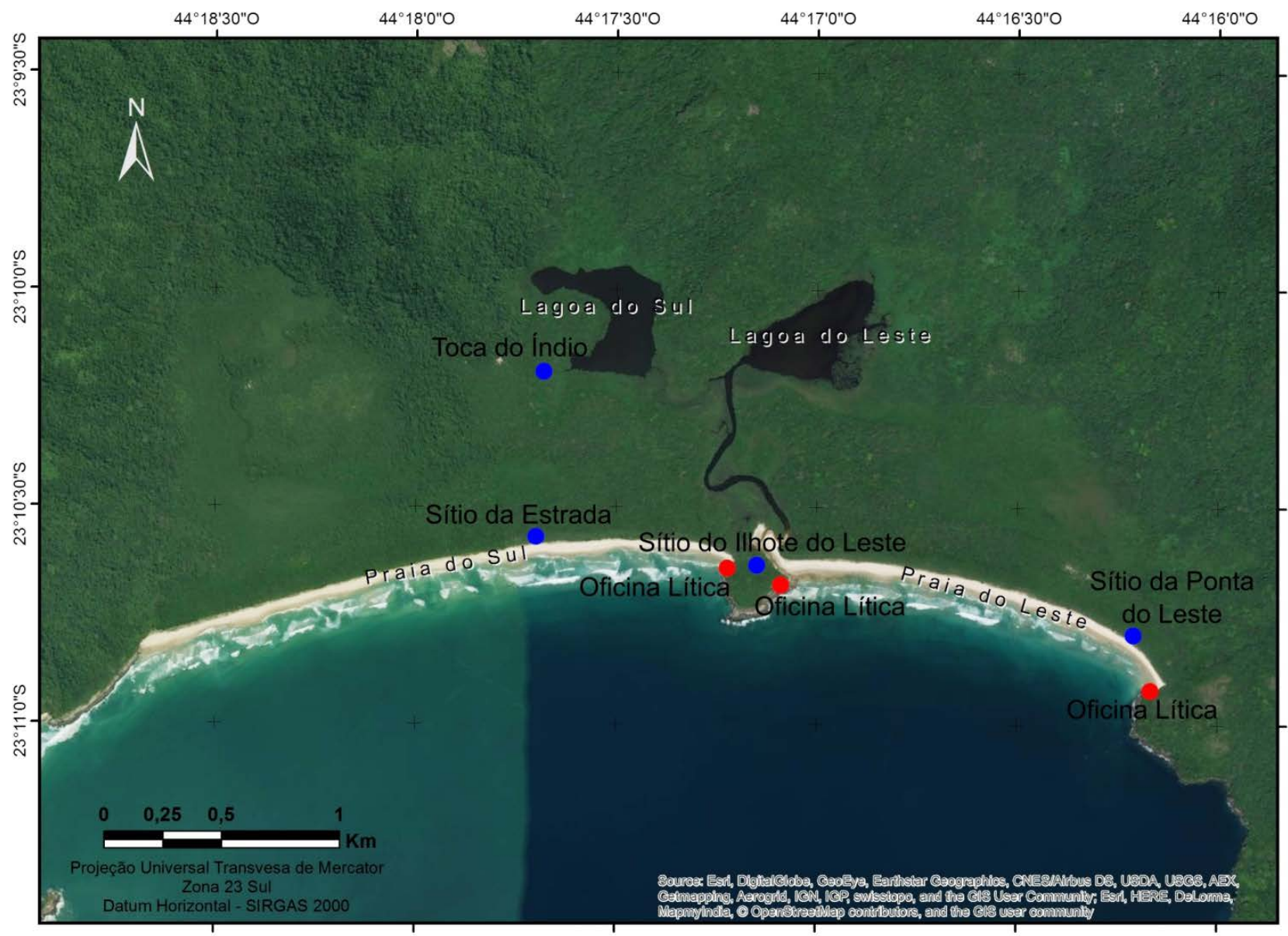

Figura 2: Área de estudo com localização dos sítios arqueológicos.

dia 23/02/2015, com rastreador de sinal GNSS modelo GTR-G2 (TechGeo), executado no modo cinemático, acoplado a uma haste com $2 \mathrm{~m}$ de altura.

Foi percorrido um caminho pré-existente com 970 $\mathrm{m}$ de extensão sobre a planície costeira da Praia do Sul, entre o mar e o ponto mais próximo possível da margem da Lagoa do Sul. Ao longo do trajeto, foram estabelecidos 15 pontos de passagem. Para a calibração com relação ao nível médio do mar, foi realizado um perfil topográfico de praia, conforme descrito em Muehe (1998) e Silva et al. (2008), no prolongamento do caminho percorrido. O perfil de praia foi obtido com o método das balizas de Emery (1961). Dia, hora e intervalo de aquisição foram anotados para ajuste com relação ao NMM e à Tábua de Marés relativa ao Porto de Angra dos Reis, fornecidos pela DHN. O perfil foi plotado em gráfico do tipo dispersão/pontos e linhas, com tipo de linha suavizada pela curva "Spline B", com resolução 4 e grau dos polinômios 2 .

\subsection{Sondagens e análises estratigráficas}

Uma estimativa da batimetria e de camadas subsuperficiais da Lagoa do Sul foi realizada com o uso do sistema portátil SyQuest Stratabox 3510, operado em $10 \mathrm{kHz}$. A perfilagem subsidiou a definição dos pontos de sondagem. Testemunhadores de alumínio com 3 polegadas de diâmetro foram introduzidos no sedimento por percussão manual, a partir do bote de apoio, até o máximo possível. Dois testemunhos, LS01 e LS02, foram abertos, analisados e subamostrados no Laboratório de Sedimentologia da UFF.

Amostras de camadas arenosas foram processadas para análise granulométrica da fração grossa, sendo lavadas em peneira $63 \mu \mathrm{m}$ e secas em estufa. Fragmentos vegetais e de conchas foram retirados manualmente e procedeu-se à análise no granulômetro CAMSIZER (Retsch Technology), para tamanho, esfericidade (SPHT) e arredondamento (RDNS). Foi realizada também avaliação visual da textura de amostras arenosas do testemunho LS01, utilizando-se uma lupa estereoscópica Zeiss 2000-C com câmera fotográfica acoplada. Os resultados relativos ao tamanho de grãos foram processados no programa Gradistat 8.0 (Blott \& Pye 2001), que baseia sua estatística em Folk \& Ward (1957). A esfericidade e o arredondamento foram avaliados segundo os padrões publicados em Blott \& Pye (2008).

Alíquotas de aproximadamente 5 gramas de 8 amostras (em duplicatas) do testemunho LS01 foram utilizadas para se obter o teor de CHN (Carbono, Hidrogênio e Nitrogênio) e permitir o cálculo da razão $\mathrm{C}: \mathrm{N}$. Para tanto, foram descarbonatadas com $\mathrm{HCl}$, congeladas, liofilizadas e processadas no analisador elementar Perkin-Elmer $2400 \mathrm{CHNS} / \mathrm{O}$, à temperatura de combustão de $950^{\circ} \mathrm{C}$, com calibração por acetanilida. 
Carapaças calcárias de moluscos foram retiradas dos dois testemunhos para identificação taxonômica por especialista. Para avaliação visual de potenciais microfósseis, 7 amostras do testemunho LS01 foram lavadas em peneira de $63 \mu \mathrm{m}$, secas em estufa a $50^{\circ} \mathrm{C}$ por 12 horas e observadas através da lupa estereoscópica Zeiss Stemi 2000-C.

Treze amostras de conchas de moluscos e uma de sedimento foram datadas ao ${ }^{14} \mathrm{C}$ AMS pelo Laboratório de Radiocarbono da UFF (LAC-UFF). Foram escolhidas as amostras de conchas mais íntegras, de modo a refletir a morte do organismo in situ, garantindo que não houve significativa descontextualização. $O$ procedimento de subamostragem e o pré-tratamento foram realizados conforme Macario (2003). As calibrações foram feitas online através do programa Calib 7.1 (Stuiver \& Reimer 1993, Reimer et al. 2013), disponível no endereço http://calib.qub.ac.uk/ calib/. Utilizou-se a curva Marine13 (com Delta $\mathrm{R}=$ $-59+/-42)$ e 2 sigma de erro ( $95,4 \%$ de confiabilidade). Os resultados são apresentados em intervalos de idade calibrada. Para as discussões, todas as idades consultadas na literatura tiveram a calibração atualizada, exceto quando não foram publicadas as idades convencionais.

\section{Resultados}

\subsection{Mapeamento}

Com base na fotointerpretação dos pares estereoscópicos, foi produzido um mapa geomorfológico (figura 3) utilizando-se as mesmas classes definidas por Amador (1988), apenas substituindo o termo "restinga" por "barreira". A análise dos dados SRTM possibilitou distinguir as feições no relevo da planície (figura 4).

\subsection{Levantamento Geodésico}

Dois cordões arenosos foram identificados, um externo, incluindo a praia e seu reverso, e um interno, próximo à lagoa. No cordão externo a altura máxima foi de 4,56 m. No cordão interno, foi de 5,73 m (figura 5). A partir da relação altimétrica entre o NMM (nível médio do mar) e o nível da Lagoa do Sul, foi possível identificar os níveis das sondagens, descontando-se a profundidade de lâmina d'água medida em cada coleta. O topo do testemunho LS01 está a 4,06 m abaixo do NMM e sua base está a 5,40 m. O topo do testemunho LS02 está a 3,86 m e sua base, a 5,25 m abaixo do NMM.

\subsection{Estratigrafia da Lagoa do Sul}

Em 02/02/2014, foi coletado o testemunho LS01 nas coordenadas $23^{\circ} 10^{\prime} 06,94$ ' $\mathrm{S} / 4^{\circ} 17^{\prime} 27,85^{\prime} \mathrm{W}$, em lâmina d'água de $1,30 \mathrm{~m}$. A penetração acústica da perfilagem com sistema Stratabox foi atenuada pela camada de lama fluida superficial e por gases em subsuperfície, porém foi possível detectar um refletor acústico em profundidade de cerca de 2 metros, onde foi definida a localização do testemunho LS02, coletado em 26/06/2014, nas coordenadas $23^{\circ} 09^{\prime} 58,78^{\prime}$ S/ $44^{\circ} 17^{\prime} 36,79^{\prime \prime} \mathrm{W}$, em lâmina d'água de 1,10 m.

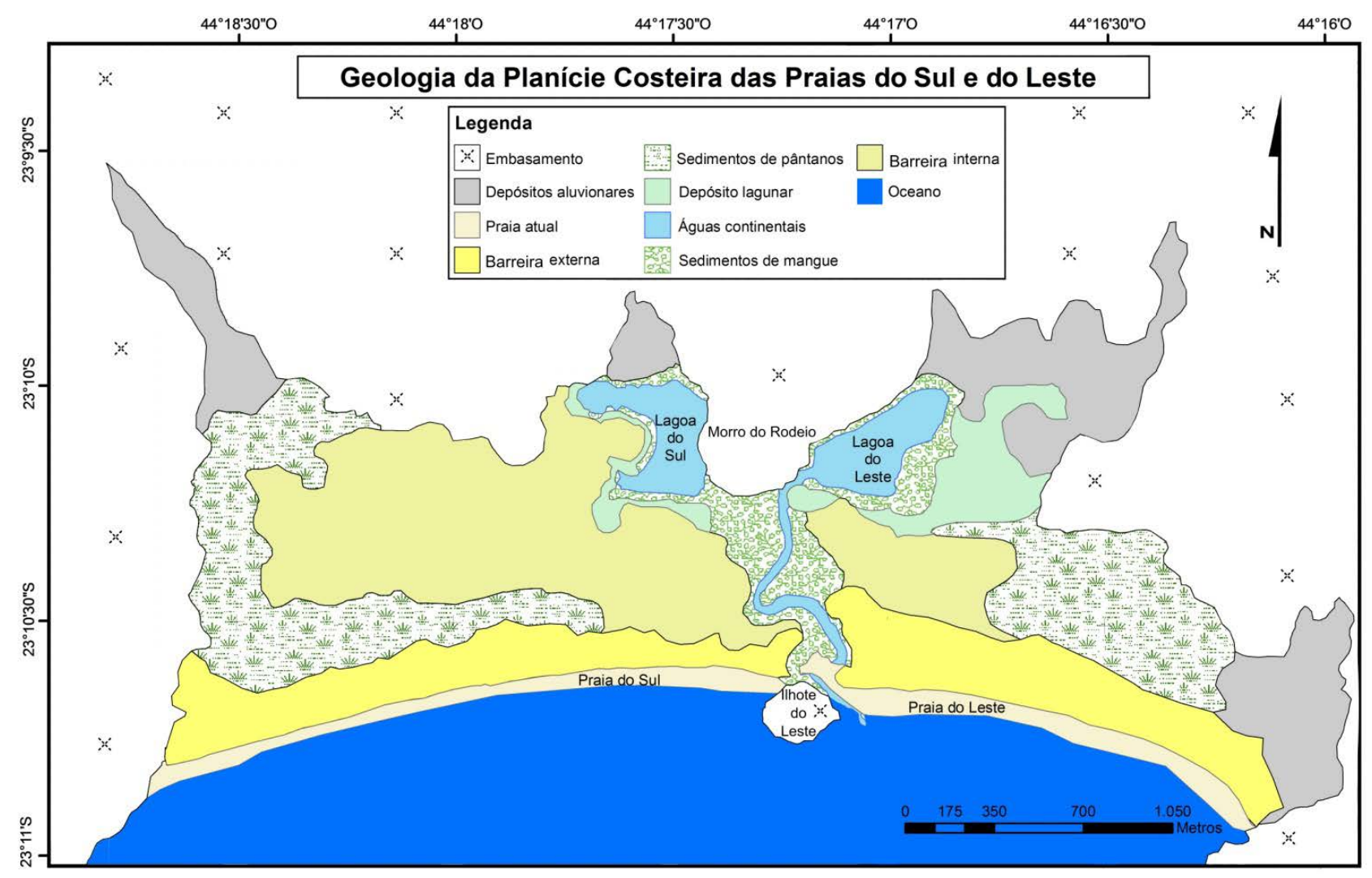

Figura 3: Mapa elaborado a partir da interpretação dos pares estereoscópicos, mantendo-se a classificação dos depósitos sedimentares conforme Amador (1988). 


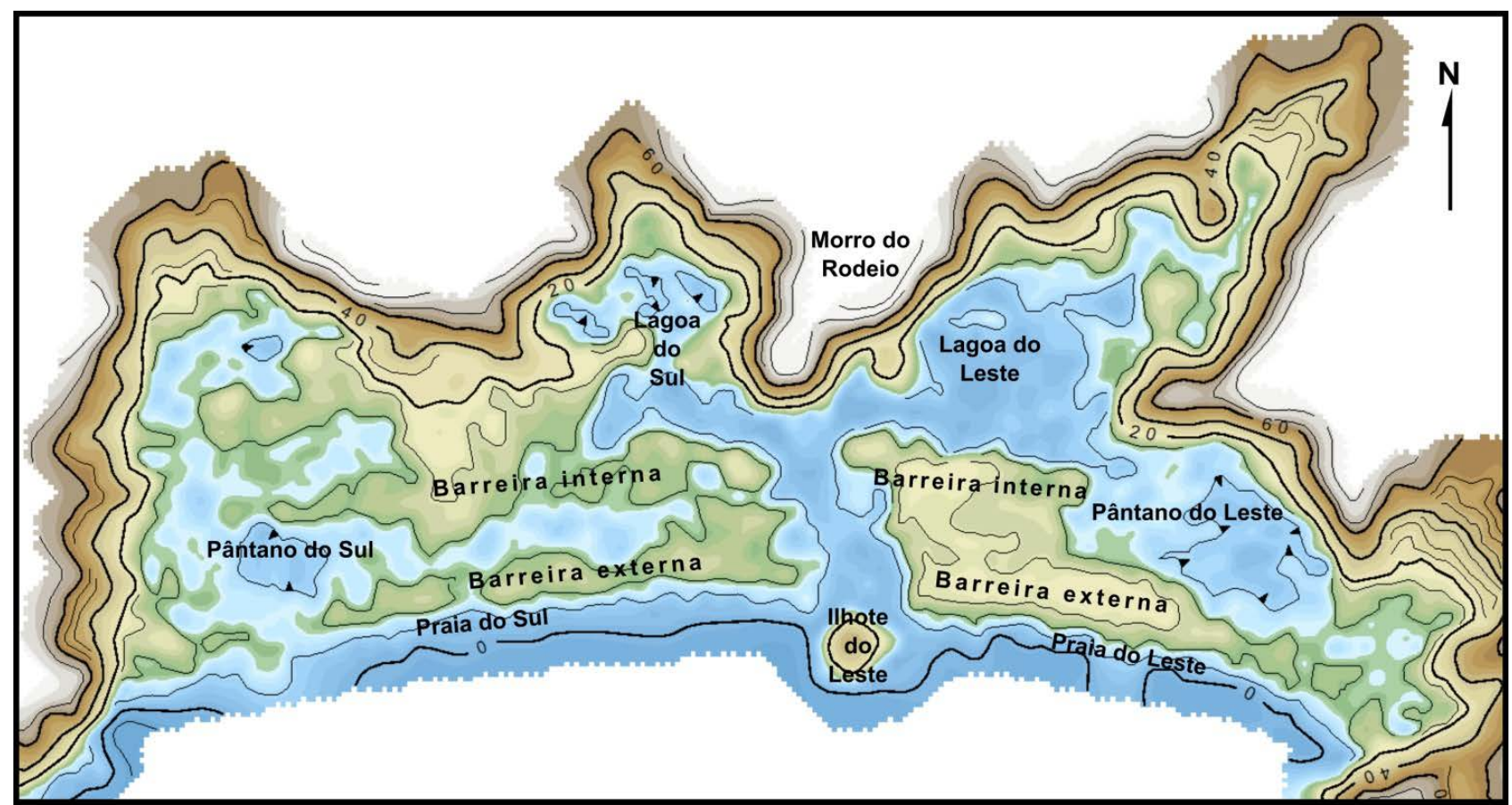

Figura 4: Relevo da planície costeira a partir de dados SRTM 30 m, com identificação das principais feições.

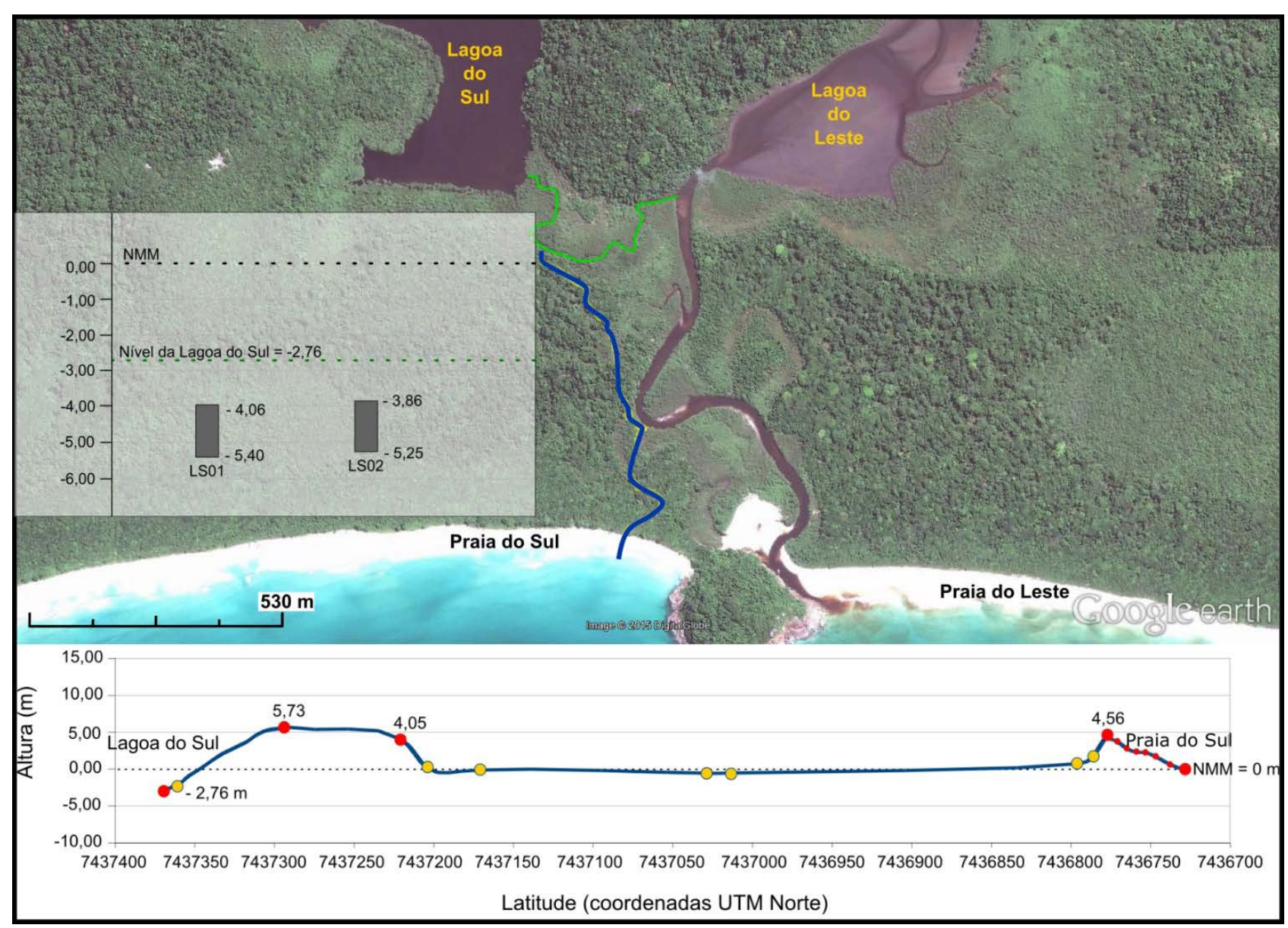

Figura 5: Sobre a imagem Google Earth ${ }^{T M}$, o percurso do levantamento topográfico está representado pela linha azul. Em verde está delineado o canal de acesso à Lagoa do Sul. Na parte de baixo nota-se o perfil topográfico, desde a Lagoa do Sul (à esquerda) até a Praia do Sul (à direita). Os pontos vermelhos apresentam maior precisão altimétrica. $\mathrm{O}$ trajeto percorrido não é retilíneo, portanto os pontos medidos estão projetados conforme a latitude, com sinuosidade desconsiderada. O quadro inserido mostra o nivelamento dos testemunhos com relação ao NMM. 


\subsubsection{Testemunho LS01}

O testemunho LS01 recuperou 1,34 m de sedimentos lamo-arenosos. A cor predominante é cinza escura, com variação quase inexistente. No topo do testemunho $(0 \mathrm{a}$ $\sim 40 \mathrm{~cm}$ ) o sedimento é homogêneo e reflete as condições observadas in situ, com o fundo da lagoa lamoso e bastante fluido. A lama é intercalada por lentes arenosas centimétricas, sendo que três lentes representam descontinuidades físicas que delimitam quatro intervalos: F1, F2, F3 e F4 (figura 6). Poucos fragmentos vegetais esparsos foram observados ao longo do testemunho.
Destaca-se a presença de diversos fragmentos de conchas de moluscos de tamanhos milimétricos a centimétricos, identificadas como: Heleobia australis (d'Orbigny 1835), Nassarius sp. (Duméril 1805) e Macoma cf. cleryana (d'Orbigny 1846). Sete amostras de conchas e uma de sedimento foram datadas ao ${ }^{14} \mathrm{C}$ (tabela 1). A partir das datações, estimaram-se as taxas de acumulação entre alguns intervalos, com uma média geral de 0,047 $\mathrm{cm} /$ ano no ponto de coleta (tabela 2) Devido a pequenas inversões observadas abaixo de $84 \mathrm{~cm}$, considerou-se 2 taxas distintas na base do testemunho.

Tabela 1: Idades de amostras do testemunho LS01.

\begin{tabular}{|c|c|c|c|c|c|}
\hline Nível & $\begin{array}{l}\text { Idade Convencional } \\
\qquad\left(\operatorname{anos}{ }^{14} \mathrm{C} \mathrm{AP}\right)\end{array}$ & Intervalos & \#LAC-UFF & Material datado & $\begin{array}{c}\text { Intervalo de idade } \\
\text { calibrada (anos cal AP) }\end{array}$ \\
\hline $37 \mathrm{~cm}$ & $997+/-85$ & F3 & 14P23A09 & M. cf. cleryana & $795-481$ \\
\hline $38 \mathrm{~cm}$ & $1.049+/-39$ & F3 & 14P23A10 & M. cf. cleryana & $771-551$ \\
\hline $70 \mathrm{~cm}$ & $1.676+/-35$ & $\mathrm{~F} 3$ & 14P23A08 & M. cf. cleryana & $1.394-1.174$ \\
\hline $84 \mathrm{~cm}$ & $2.136+/-24$ & $\mathrm{~F} 2$ & 14P43A07 & Nassarius sp. & $1.920-1.663$ \\
\hline $102 \mathrm{~cm}$ & $2.441+/-42$ & $\mathrm{~F} 2$ & 14P23A06 & M. cf. cleryana & $2.307-2.002$ \\
\hline $103 \mathrm{~cm}$ & $2.594+/-47$ & $\mathrm{~F} 2$ & 14P50A03 & Sedimento & $2.552-2.147$ \\
\hline $104 \mathrm{~cm}$ & $2.584+/-37$ & $\mathrm{~F} 2$ & 14P23A07 & H. australis & $2.493-2.149$ \\
\hline $116 \mathrm{~cm}$ & $2.568+/-41$ & $\mathrm{~F} 1$ & 14P23A04 & H. australis & $2.477-2.138$ \\
\hline
\end{tabular}

Tabela 2: Taxas de acumulação ao longo do testemunho LS01.

\begin{tabular}{ccc}
\hline $\begin{array}{c}\text { Intervalo de } \\
\text { nível }(\mathbf{c m})\end{array}$ & $\begin{array}{c}\text { Taxa de } \\
\text { acumulação }\end{array}$ & OBS: \\
\hline $0-37$ & $0,058 \mathrm{~cm} /$ ano & Intervalo F4 \\
\hline $38-70$ & $0,051 \mathrm{~cm} /$ ano & Intervalo F3 \\
\hline $70-84$ & $0,028 \mathrm{~cm} /$ ano & $\begin{array}{c}\text { Topo do } \\
\text { intervalo F2 }\end{array}$ \\
\hline $84-103$ & $0,034 \mathrm{~cm} /$ ano & $\begin{array}{c}\text { Base do intervalo F2 } \\
\text { Base do intervalo F2 e } \\
\text { topo de F1 }\end{array}$ \\
\hline
\end{tabular}

Carapaças de ostracodes no nível de $84 \mathrm{~cm}$ foram identificadas como Cyprideis cf. torosa, com possibilidade de haver outra espécie. A análise granulométrica das areias indicou que as três descontinuidades físicas $(36 \mathrm{~cm}, 73 \mathrm{~cm}$ e $110 \mathrm{~cm}$ ) são compostas por areia média moderadamente selecionada, com distribuição polimodal, simétrica e mesocúrtica, sendo que a camada mais rasa (recente) é ligeiramente cascalhosa (slightly gravelly sand). São compostas principalmente por grãos de quartzo, com presença de outros minerais, inclusive minerais pesados. O grau de arredondamento é bastante similar entre as três amostras, com grãos sub-arredondados $(\mathrm{RDNS}=0,25-0,5)$ e alta esfericidade $(\mathrm{SPHT}=0,775$ 0,894). A razão C:N encontrada variou entre 14,46 e 21,71 (figura 7), intervalo que, segundo a literatura (Meyers 1997, Meyers \& Ishiwatari 1993, Stein 1991, Saito et al. 1989), é característico de origem mista a terrestre da matéria orgânica presente no sedimento.

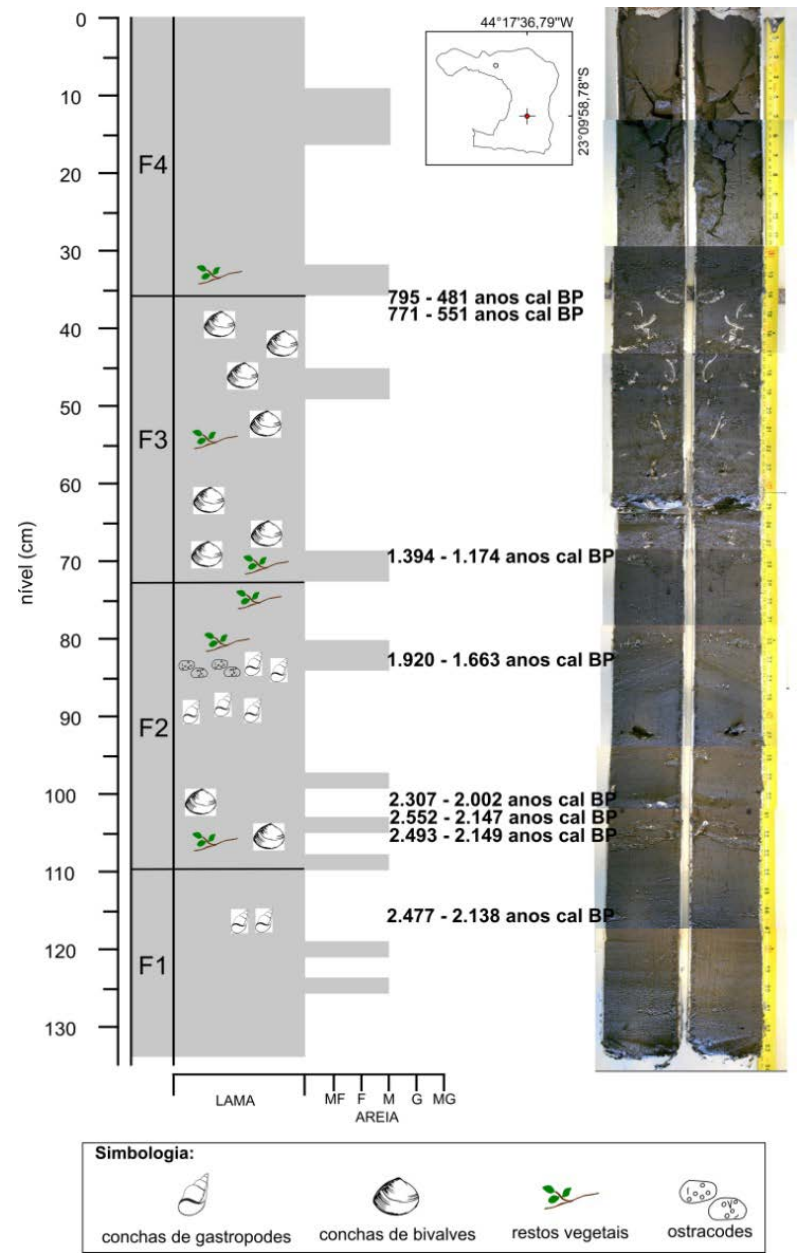

Figura 6: Perfil esquemático do testemunho LS01, com fotografias, cronologia e representação de indicadores paleoambientais. 


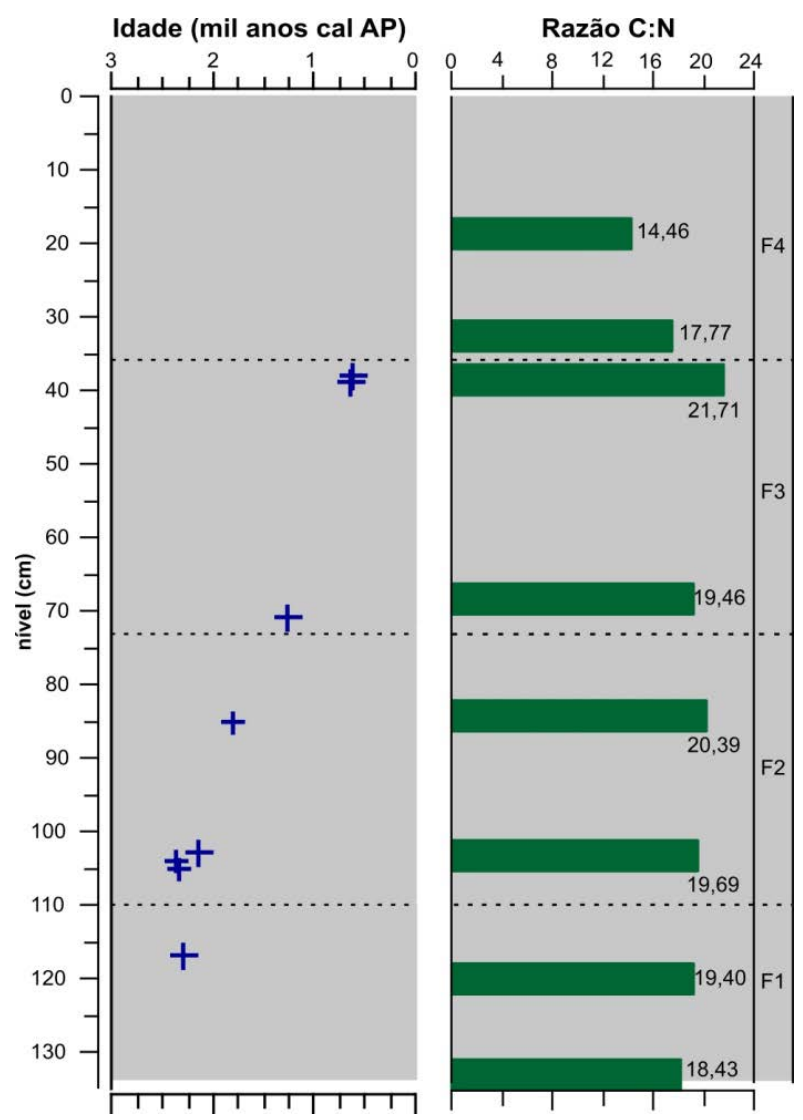

Figura 7: Correlação entre as idades calibradas e a razão C:N em diferentes níveis do testemunho LS01.

\subsubsection{Testemunho LSO2}

O sedimento no testemunho LS02, com 1,39 m, apresentou também coloração cinza escura, com variação próximo à base, a $115 \mathrm{~cm}$ (ca. 4.400 anos $\mathrm{AP}$ ), onde o sedimento é mais claro na parte superior, mais recente. Apresentou cinco intervalos, denominados L1, L2, L3, L4 e L5 (figura 8), constituídas basicamente por lama arenosa, intercaladas por lentes arenosas centimétricas, geralmente associadas à presença de conchas e fragmentos de conchas de moluscos bivalves e gastrópodes. As espécies de moluscos identificadas foram: Heleobia australis (d'Orbigny 1835), Macoma cf. cleryana (d'Orbigny 1846), Cerithium atratum (Born 1778) e Anomalocardia flexuosa (Linnaeus 1767). Um exemplar do gastrópode Cerithium atratum foi depositado na coleção malacológica do Museu Nacional da UFRJ, sob o número 34.147. Não foram realizadas análises microscópicas neste testemunho. Os sedimentos da lâmina de areia entre L1 e L2, na base, continham acúmulo peculiar de conchas de Anomalocardia flexuosa. Foram datadas seis amostras de conchas de moluscos (tabela 3). A partir das datações obtidas, estimaram-se as taxas de acumulação dos intervalos e uma média geral de $0,024 \mathrm{~cm} /$ ano no ponto de coleta (tabela 4).

\section{Discussão}

\subsection{Evolução geomorfológica}

A fim de propiciar uma correlação mais precisa com os dados do presente estudo, selecionaram-se alguns indicadores utilizados por Angulo \& Lessa (1997) coletados entre Cabo Frio e Santos, para compor uma curva regional de variação do nível relativo do mar (figura 9). Admitindo-se, pela análise da curva, a inexistência das oscilações de alta frequência do nível relativo do mar durante o Holoceno, propostas por Suguio et al. (1985) e Martin et al. (1986, 1987), que pautaram as interpretações elaboradas por Amador (1988), a evolução da planície costeira das Praias do Sul e do Leste pode ser sensivelmente diferente.
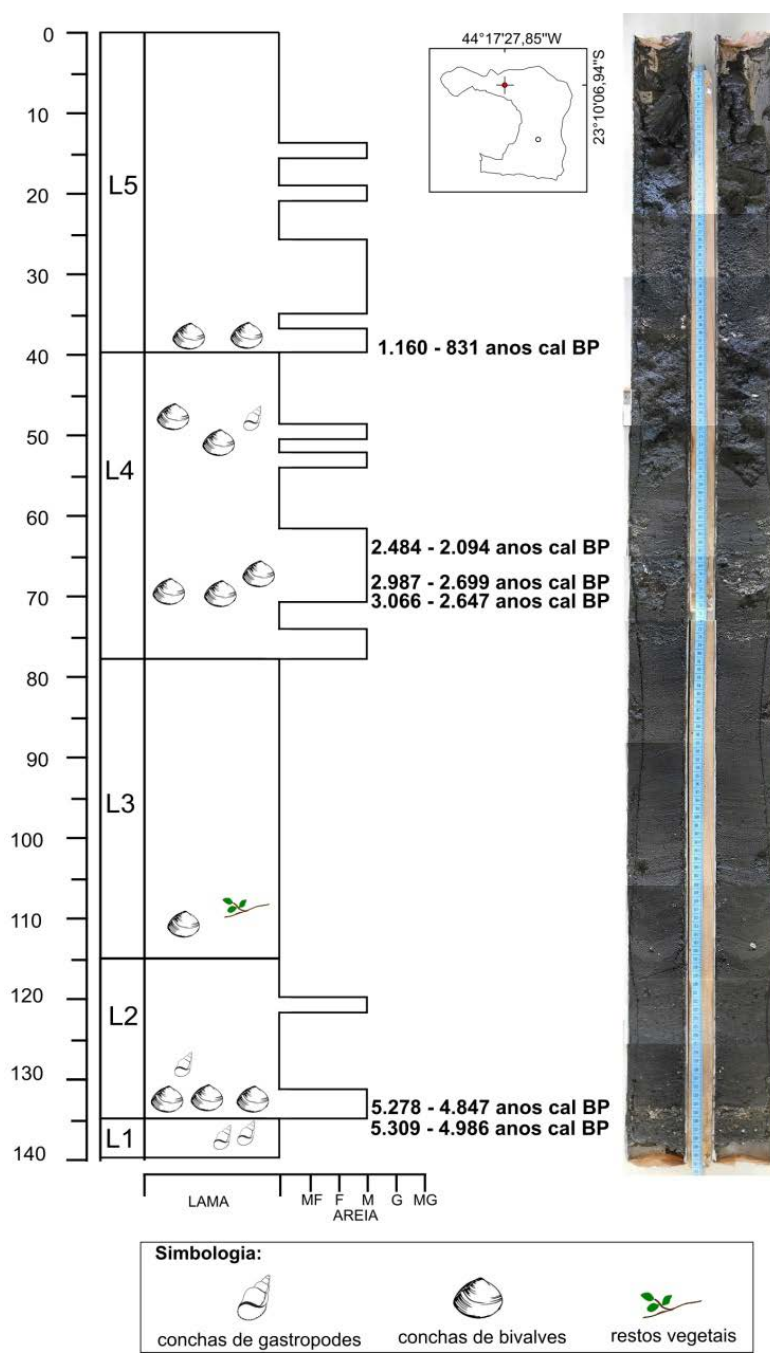

Figura 8: Perfil esquemático do testemunho LS02, com fotografias, cronologia e representação de paleoindicadores.

Segundo Dias \& Kjerfve (2009), a gênese das barreiras arenosas deve-se às variações relativas do nível do mar, em que eventos transgressivos transportam sedimentos da plataforma continental para a costa, promovendo acresção e formação de terraços. Portanto, pode-se afirmar que as duas barreiras observadas neste estudo (figuras 3 e 4) são registros de dois eventos transgressivos.

Amador (1988) vinculou suas formações às transgressões marinhas propostas por Suguio et al. (1985) e Martin et al. (1987) entre 6.000 e 5.000 anos AP e entre 3.800 e 3.000 anos AP. Entretanto, a atualização das interpretações de indicadores de paleoníveis marinhos conduziu à reinterpretação da evolução de várias planícies costeiras do Brasil (Angulo et al. 2006). 
Tabela 3: Idades de amostras do testemunho LS02.

\begin{tabular}{cccccc}
\hline Nível & $\begin{array}{c}\text { Idade Convencional } \\
\text { (anos }{ }^{14} \mathbf{C} \text { AP) }\end{array}$ & Intervalos & \#LAC-UFF & Material datado & $\begin{array}{c}\text { Intervalo de idade calibrada } \\
\text { (anos cal AP) }\end{array}$ \\
\hline $39 \mathrm{~cm}$ & $1.376+/-55$ & L5-L4 & 14P43A01 & M. cf. cleryana & $1.160-831$ \\
\hline $64 \mathrm{~cm}$ & $2.548+/-56$ & L4 & 14P43A02 & H. australis & $2.484-2.094$ \\
\hline $70 \mathrm{~cm}$ & $2.986+/-53$ & L4 & 14P43A03 & M. cf. cleryana & $2.987-2.699$ \\
\hline $70 \mathrm{~cm}$ & $2.981+/-77$ & L4 & 14P43A04 & H. australis & $3.066-2.647$ \\
\hline $134 \mathrm{~cm}$ & $4.730+/-73$ & L2-L1 & 14P43A05 & M. cf. cleryana & $5.278-4.847$ \\
\hline $136 \mathrm{~cm}$ & $4.811+/-36$ & L1 & 14P43A08 & C. atratum & $5.309-4.986$ \\
\hline
\end{tabular}

Tabela 4: Taxas de acumulação ao longo do testemunho LS02.

\begin{tabular}{ccc}
\hline $\begin{array}{c}\text { Intervalo de } \\
\text { nível }(\mathbf{c m})\end{array}$ & $\begin{array}{c}\text { Taxa de } \\
\text { acumulação }\end{array}$ & OBS: \\
\hline $0-39$ & $0,039 \mathrm{~cm} /$ ano & Intervalo L5 \\
\hline $39-64$ & $0,019 \mathrm{~cm} /$ ano & Topo ao centro de L4 \\
\hline $64-70$ & $0,011 \mathrm{~cm} /$ ano & $\begin{array}{c}\text { Camada arenosa com } \\
\text { acúmulo biodetrítico (L4) }\end{array}$ \\
\hline $70-135$ & $0,029 \mathrm{~cm} /$ ano & $\begin{array}{c}\text { Base de L4 até a base do } \\
\text { testemunho (L1) }\end{array}$ \\
\hline
\end{tabular}

Ao se observar que após o máximo holocênico o nível relativo do mar mostra uma tendência geral de rebaixamento até os dias atuais (figura 9), sem variações de curto período, tornou-se plausível o entendimento de que as barreiras arenosas mais internas que a barreira holocênica são resultantes de transgressões marinhas pleistocênicas. Assim, entende-se que a barreira interna da planície costeira das Praias do Sul e do Leste se formou no Pleistoceno, entre $\sim 125.000$ e 80.000 anos AP, durante os estágios isotópicos MIS $5 \mathrm{a}, 5 \mathrm{c}$ ou $5 \mathrm{e}$, de acordo com as definições utilizadas por Lisiecki \& Raymo (2005) e Rabineau et al. (2006) e com as interpretações preconizadas por Rocha et al. (2013) para o norte fluminense. A barreira externa iniciou a sua formação no Holoceno, próximo ao nível de mar mais alto da transgressão holocênica, ocorrido entre 5.000-6.000 anos cal AP.

A influência da variação do nível do mar sobre o nível da Lagoa do Sul merece atenção para reconstruções paleoambientais. O confinamento da lagoa contra o Morro do Rodeio, durante a formação da barreira interna, limitou fortemente sua vazão e por isso o canal que a liga ao canal principal é estreito $(\sim 2-3 \mathrm{~m})$, raso $(\sim 0,40-$ $1,20 \mathrm{~m})$ e arenoso. Com a restrição do fluxo entre a lagoa e o canal principal (que conecta ao mar), a pluviosidade assumiu um papel preponderante na variação do nível da Lagoa do Sul. Entende-se, portanto, que o nivelamento realizado reflita uma condição transitória, com a referência altimétrica baseada em somente um levantamento, efetuado em período de condições de baixa pluviosidade em âmbito regional. A diferença de nível medida (-2,76 m; Figura 5) coincidiu com um momento em que a lagoa estava sujeita a forte escassez de aporte fluvial.

Em certos pontos das margens das lagoas, como por exemplo, na margem S e SW da Lagoa do Leste, as imagens aéreas mostram feições similares a terraços lagunares, onde é provável que haja indicadores de paleoníveis. Porém, devido ao exposto acima,

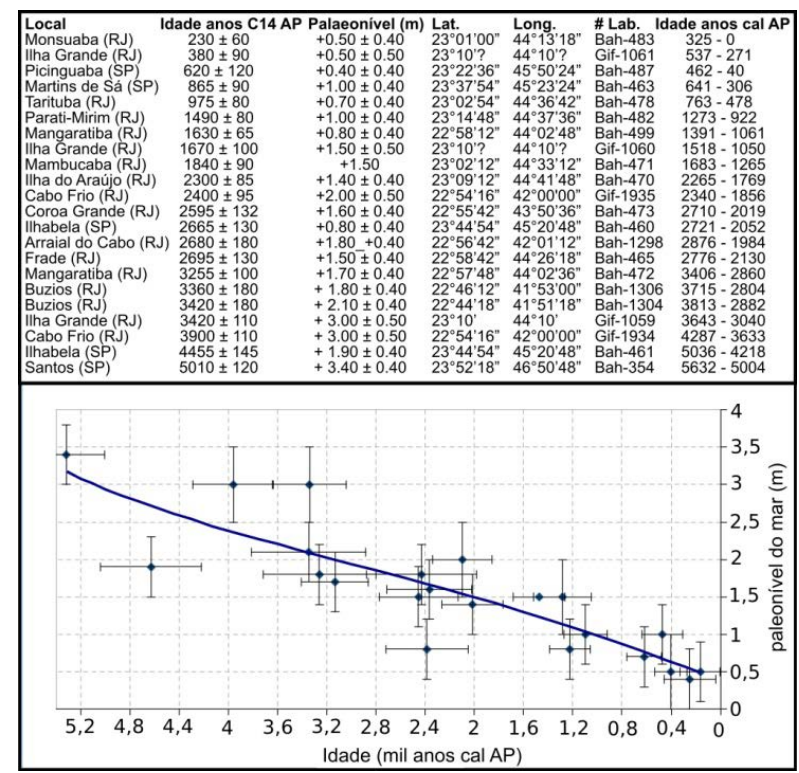

Figura 9: Dados relativos à região entre Cabo Frio (RJ) e Santos (SP), a partir de 5.000 anos AP, de amostras de vermetídeos utilizados por Angulo \& Lessa (1997) para construção da curva de variação relativa do nível do mar. A curva de tendência em azul foi traçada a partir do polinômio de $4^{\circ}$ grau.

alterações na deposição sedimentar das margens se devem sobretudo às pulsações próprias do sistema hidrológico, fruto de eventos ou mudanças paleoclimáticas que alteram o regime pluviométrico, e não estão relacionadas unicamente às flutuações do nível relativo do mar, especialmente na Lagoa do Sul.

A altura da barreira holocênica na Praia do Leste chama atenção (figura 4). É onde possivelmente se encontra o ponto mais alto da planície e sua morfologia corresponde a uma duna frontal estabelecida, conforme definições de Hesp (2002), formada em decorrência da ação dos ventos provocados pela entrada de frentes frias, vindas da direção $\mathrm{S} / \mathrm{SW}$. Estes ventos, ainda que intermitentes, empilharam paulatinamente os sedimentos, construindo um capeamento eólico que aumentou a altura da barreira, enquanto era colonizada por espécies herbáceas e arbustivas.

Os dados SRTM mostram altitudes bastante similares entre a barreira pleistocênica na Praia do Sul e as duas barreiras na Praia do Leste (figura 4), de 14 a $16 \mathrm{~m}$, superestimados pela cobertura da vegetação. Na Praia do Sul, a barreira holocênica não é tão elevada provavelmente porque a energia das ondas deve ser maior nesta praia, provocando erosão da barreira. Em eventos extremos, leques de transposição devem ter se formado no reverso. 
O Ilhote do Leste parece ter servido como proteção à porção leste da planície costeira, tendo constituído uma zona de sombra das ondas vindas de SW e favorecendo maior acúmulo de sedimentos nas barreiras desta porção da planície. Com o nível do mar mais alto, a barreira interna conduzia a vazão do antigo Pântano do Leste (e possivelmente da Lagoa do Leste também) na direção do canto oriental da planície. Com o nível do mar próximo ao atual, a foz do canal adjacente ao ilhote também deve ter passado a contribuir para a proteção aos efeitos erosivos das ondas, com seu fluxo reduzindo a ação direta das ondas sobre a barreira externa. Durante o Holoceno, a desembocadura do canal provavelmente se manteve no canto da Praia do Leste e nunca no canto da Praia do Sul, do lado oposto do ilhote, devido à incidência predominante de ondas de S e SW, que induzem uma corrente litorânea na direção E, transportando sedimentos nesta mesma direção e bloqueando a possível vazão do canal da Praia do Sul.

As análises do relevo indicam que as planícies fluvio-lagunares (paleolagunas) se conectavam com o mar pelos extremos ocidental e oriental do arco praial (figura 4). As barreiras holocênicas naquelas áreas possuem a altura reduzida, sendo provável que tenha havido desembocaduras nestes extremos após a formação da barreira externa.

\subsection{Implicações sobre a ocupação humana}

Segundo Tenório (2003), as oficinas líticas (amoladores-polidores fixos) foram elaboradas preferencialmente em locais próximos a cursos d'água para facilitar o trabalho de amolar e polir as ferramentas com o uso de água e areia. No canto ocidental da Praia do Sul não há amoladores, mas no costão oriental da Praia do Leste há uma grande concentração, vizinha ao Sítio Arqueológico da Ponta do Leste. Este sítio e os amoladores podem ter a mesma idade de início da formação da barreira externa e da conexão da paleolaguna do Leste com o mar $(6.000-5.000$ anos cal AP).

O Sítio Arqueológico da Ponta do Leste é caracterizado por um sepultamento no substrato arenoso da barreira costeira, envolto em cinzas e carvões de fogueiras. A determinação da idade deste sítio por Tenório (2003) refere-se à datação de amostras de carvão, que apresentaram resultados de $2.880 \pm 40$ anos AP (3.140 - 2.880 anos cal AP). Não há dados disponíveis de datações do esqueleto humano. Considerando-se a idade da barreira externa, este sítio pode ser mais antigo que o sítio do Ilhote, já que o acesso ao local não era dificultado pelo nível mais alto do mar, como possivelmente ocorria com relação ao Ilhote do Leste. É provável que o estabelecimento do sítio do Ilhote tenha se iniciado há cerca de 3.000 anos cal AP devido ao fato de que naquela época o nível do mar, em processo de rebaixamento, passou a facilitar $\mathrm{o}$ acesso àquele território. Até então, o ilhote estaria literalmente isolado e batido pelo mar, que estava a mais de 2 metros acima do nível atual. Com o nível relativo do mar em rebaixamento, alcançando entre 1,5 e 2 metros acima do atual, a ocupação do ilhote teria se iniciado (figura 9).

O sítio arqueológico da Ilha do Algodão, em Angra dos Reis, situado a pouco mais de $20 \mathrm{~km}$ para NO da Ilha Grande, foi datado em $7.860 \pm 80$ anos AP (8.980 - 8.420 anos cal AP) (Lima et al. 2004, Anjos et al. 2010), constituindo um dos mais antigos registros de ocupação costeira no país. Neste contexto, questionase se os fabricantes de machado da Ilha Grande não teriam relação com os ocupantes da Ilha do Algodão, já que esta se encontra em águas abrigadas navegáveis em canoas a remo. Portanto, pode-se inferir a possibilidade de terem estabelecido outros sítios além do Ilhote do Leste, muito antes de 3.000 anos cal AP.

É plausível que os sambaquieiros tenham testemunhado parte da transgressão holocênica e por isso tenham deixado registros que se encontram atualmente submersos. Neste trabalho, foram identificados amoladores localizados abaixo do nível de maré baixa. Um deles se encontra na Praia do Leste e outro está na Praia Preta, vertente nordeste da Ilha Grande (figura 10). As marcas de produção das ferramentas, em ambas as oficinas líticas, possuem incrustação de organismos marinhos vivos, algas e cracas, o que garante que essas rochas se encontram atualmente na zona entre-marés. Acredita-se que os sambaquieiros tenham fabricado as ferramentas sempre na zona de supralitoral, acima do nível das marés mais altas.

\subsection{Sedimentação}

Amador (1988) afirma que o sistema lagunar primitivo era composto por cinco lagunas e que desde sua formação todas vem sofrendo assoreamento e dissecação. As duas atuais eram consideravelmente maiores, relacionadas a talvegues profundos, e por isso ainda remanescem. Contudo, existe uma diferença considerável de batimetria entre as duas lagoas. Nos dias de coleta e levantamentos, a Lagoa do Leste apresentava lâmina d'água em torno de $0,5 \mathrm{~m}$ no máximo, enquanto na Lagoa do Sul, a profundidade máxima passava de $2 \mathrm{~m}$. Nota-se em imagens Google Earth (figura 5) o assoreamento mais avançado da Lagoa do Leste, provavelmente por estar associada a um sistema fluvial com maior aporte de sedimentos.

A cronologia do testemunho LS02 alcançou idades muito anteriores $(5.309-4.986$ anos cal AP em $136 \mathrm{~cm})$ às idades obtidas no testemunho LS01 (2.477 - 2.138 anos cal AP em $116 \mathrm{~cm})$. A diferença considerável na taxa de acumulação média $(0,047 \mathrm{~cm} /$ ano x $0,024 \mathrm{~cm} /$ ano) indica maior erosão provocada por variações de vazão intermitente do córrego próximo do local da sondagem LS02, na margem Norte da Lagoa do Sul (figuras 6 e 8 ).

Entre 5.309 - 4.986 anos cal AP e o presente, os sedimentos da Lagoa do Sul são ricos em matéria orgânica e argilo-minerais, o que denota, em conjunto com os índices de razão $\mathrm{C}: \mathrm{N}$, origem mista a terrestre. Entende-se, portanto, que o ambiente lagunar não se 


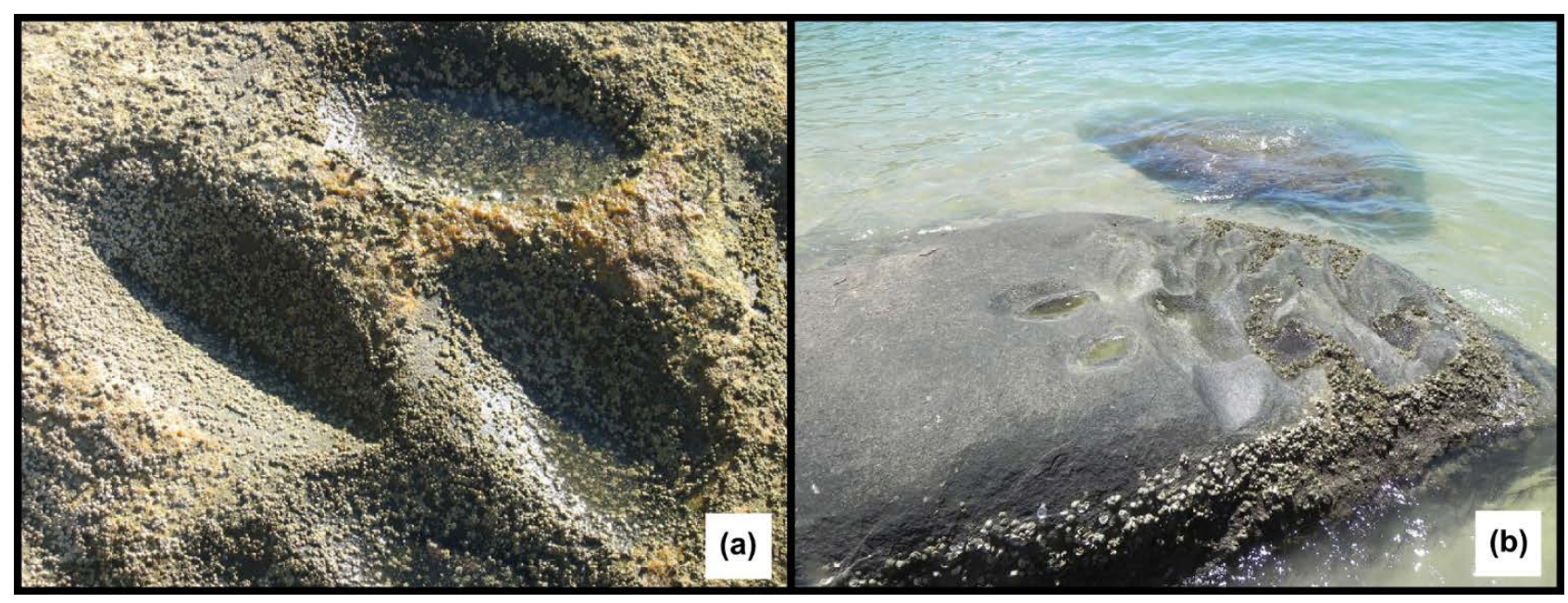

Figura 10: Amoladores-polidores-fixos elaborados em nível de mar mais baixo do que o atual. (a) localizado no canto da Praia do Leste

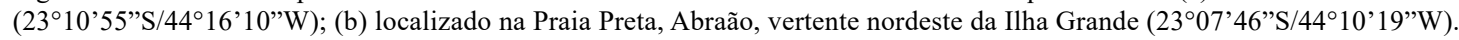

modificou significativamente neste intervalo de tempo, sendo ocupado por manguezais em suas margens, com características similares às atuais.

As camadas intercaladas de sedimentos mais grossos correspondem a eventos de chuvas extremas na bacia hidrográfica, típicos da região. Os grãos de quartzo das lentes arenosas são de tamanho médio, no entanto, são sub-arredondados, sugerindo retrabalhamento marinho por ondas sobre a barreira costeira. Ocorreram enxurradas de maior destaque em 795 - 481 anos cal AP, $1.394-1.174$ anos cal AP e $2.382-2.079$ anos cal AP (estimada por interpolação). No testemunho LS02, há uma distinção na sedimentação entre dois intervalos: (i) de 5.309 - 4.986 a 3.066 - 2.647 anos cal AP e (ii) entre 3.066 - 2.647 anos cal AP e o presente. No intervalo mais antigo, o sedimento lamoso possui raras lentes arenosas. No intervalo mais recente, há muitas camadas arenosas. Esta diferença leva a inferir que ocorreram enxurradas com maior frequência após $3.066-2.647$ anos cal AP.

Ao longo de toda a sequência recuperada, a maior diferença na deposição está na base do testemunho LS02 (5.309 - 4.986 a 5.278 - 4.847 anos cal AP), revelando uma mudança substancial no ambiente. Apesar de ser uma porção estreita do intervalo L1, admite-se que seja o topo do refletor sísmico detectado. A experiência durante a sondagem reforça a hipótese, pois ao se manipular o testemunhador para a penetração foi possível sentir nesta profundidade $(\sim 1,35 \mathrm{~m})$ a textura arenosa característica. $\mathrm{O}$ alto teor de conchas distintas dos demais intervalos, com destaque para o grande acúmulo do bivalve Anomalocardia flexuosa, dá indícios de que se trata de um depósito peculiar, relacionado a algum evento ou período extraordinário, ocorrido em um tempo próximo ao nível de mar mais alto no Holoceno.

\subsection{Paleoclima}

Ybert et al. (2003), a partir de estudos em sedimentos orgânicos de uma floresta alagada da planície costeira da região de Cananéia-Iguape (SP), a cerca de $370 \mathrm{~km}$ a sudoeste da Ilha Grande (mesmo domínio climático e ambiental), afirmam que no período compreendido entre ca. 5.000 anos cal AP e o presente, o clima não mudou significativamente, exceto por três episódios ligeiramente mais úmidos: (i) entre 3.410 e 2.615 anos cal AP, (ii) ca. 1.695 anos cal AP e (iii) entre 1.300 e 660 anos cal AP, sendo este último o mais úmido.

O período mais úmido indicado por Ybert et al. (2003) coincide com a idade do intervalo F3 do testemunho LS01, datado entre $1.394-1.174$ anos cal AP e $795-$ 481 anos cal AP, onde é marcante a ocorrência numerosa de carapaças calcárias de Macoma cf. cleryana. A razão $\mathrm{C}: \mathrm{N}$ no nível relativo à 795 - 481 anos cal AP é a maior de toda a coluna (figura 7), reforçando maior aporte de terrígenos, onde há maior concentração de conchas íntegras do bivalve em posição de vida.

\subsection{Paleoecologia}

Foram identificados seis taxa: dois moluscos bivalves, três gastrópodes e um crustáceo ostracode. Cyprideis torosa e Anomalocardia flexuosa são potencialmente bons indicadores de paleoambientes, merecendo estudos futuros para reconstituição paleoecológica da região.

C. torosa, encontrado no nível de $84 \mathrm{~cm}$ e datado em 1.920 - 1.663 anos cal AP, é uma espécie de ostracode eurihalina e euritérmica que modifica a carapaça conforme a salinidade (Boomer \& Frenzel 2011). Estudos morfométricos e analíticos da sua carapaça podem trazer importantes resultados com relação à paleo-salinidade.

Segundo Angulo \& Souza (2014), a altura do topo de bancos de conchas de Anomalocardia flexuosa indica paleonível médio de baixa-mar na época de vida dos indivíduos. Como neste trabalho sua ocorrência foi identificada somente em nível submerso, seria interessante investigar sua presença em terraços emersos. Em todo caso, sua presença em 5.309 - 4.986 anos cal AP, quando se estima que o nível relativo do mar esteve cerca de 3 metros acima do atual, é condizente com um ambiente de maior salinidade e maior aporte de areias marinhas. 
De acordo com Tenório (2003, 2006) e Tenório et al. (2008), nas escavações arqueológicas do sítio do Ilhote do Leste foram identificados e datados organismos de sete taxa, seis moluscos bivalves e um gastrópode, são eles: Ostrea sp., Phacoides pectinatus, Olivancillaria auricularia, Iphigenia brasiliensis, Tagelus plebeius, Macoma constricta e Anomalocardia flexuosa. Apenas uma espécie e um gênero são comuns ao presente estudo (A. flexuosa e Macoma sp). Atribui-se esta diferença ao fato de que no sambaqui foram depositadas somente carapaças de organismos que servem para alimentação humana, coletados em distintos ambientes (canal, praias, costões e manguezais), enquanto nos testemunhos estratigráficos deste trabalho, os organismos foram coletados in situ unicamente no fundo das lagoas.

\section{Conclusões}

Duas barreiras costeiras foram identificadas na planície costeira estudada. A interna pode ter se formado no Pleistoceno, entre 125.000 e 80.000 anos AP, e a externa começou a se formar entre $6.000-5.000$ anos cal AP, próximo ao nível de mar mais alto no Holoceno. Ambas as lagoas se encontram à retaguarda da barreira interna, portanto, foram formadas pela primeira vez no Pleistoceno. O nível da água das lagoas e consequentemente as alterações na deposição das suas margens dependem principalmente de mudanças paleoclimáticas afetando o regime pluviométrico, e nem tanto das marés e das variações do nível relativo do mar.

A barreira externa na Praia do Leste se destaca pela altura, correspondendo à presença de dunas frontais, formadas em decorrência da ação dos ventos de tempestades, de direção S/SW. Na Praia do Sul, a barreira externa não é tão elevada, pois a energia das ondas se sobressai, erodindo a barreira. Em eventos extremos, leques de transposição devem ter se formado no reverso. As paleolagunas, atuais pântanos, se conectavam com o mar pelos extremos ocidental e oriental do arco praial.

A maior concentração de oficinas líticas está no costão rochoso vizinho à paleo-desembocadura do pântano do Leste e ao Sítio Arqueológico da Ponta do Leste, que pode ter idades de até $6.000-5.000$ anos cal AP (idade da barreira externa onde se encontra), e desta forma ser mais antigo que o Sítio do Ilhote.

As lagoas atuais encontram-se em processo de assoreamento e dissecação, mais avançado na Lagoa do Leste. As propriedades sedimentológicas analisadas entre 5.309 - 4.986 anos cal AP e o presente indicam origem mista a terrestre da matéria orgânica, com variações irrelevantes, permitindo dizer que aquele ambiente não se modificou significativamente desde então. Períodos com maior frequência de chuvas extremas na bacia hidrográfica geraram a deposição intercalada de camadas centimétricas de sedimentos arenosos, com características granulométricas que sugerem origem na barreira interna em 795 - 481 anos cal AP, 1.394 - 1.174 anos cal AP e 2.382 - 2.079 anos cal AP. Entre 3.066 - 2.647 anos cal AP e o presente ocorreram enxurradas com maior frequência do que entre $5.309-4.986$ anos cal AP e 3.066 - 2.647 anos cal AP. O intervalo entre $1.394-1.174$ anos cal AP e 795 - 481 anos cal AP é o período mais úmido, com ocorrência marcante de carapaças do bivalve Macoma $\mathrm{cf}$. cleryana. Os sedimentos da base da sondagem LS02, datada entre 5.309 - 4.986 e 5.278 - 4.847 anos cal AP, condizem com uma mudança substancial no ambiente, coerente com a idade do máximo holocênico, com maior teor de areias e acúmulo de conchas de Anomalocardia flexuosa.

Das espécies identificadas, o ostracode Cyprideis torosa e o bivalve Anomalocardia flexuosa merecem estudos aprofundados por serem potenciais indicadores para reconstituição paleoambiental da região.

\section{Agradecimentos}

Aos auxiliares de campo Renato Motta, Alexandre Cuellar e Roberto Cardoso (in memoriam). Aos funcionários da RB Praia do Sul (INEA) Criste, Edinaldo e Fábio. Ao MSc. Fabrício Ferreira (UFF) e ao MSc. Lucas Antonietto (UnB), pela identificação de ostracodes. Ao Dr. Alexandre Pimenta (MN/UFRJ), pela identificação de moluscos. À Dra. Kita Macario e à Maria Isabela Oliveira (LAC-UFF), pelas datações. Aos revisores anônimos pelas ricas críticas e sugestões ao manuscrito. À CAPES pela bolsa de mestrado para Rafael Cuellar de Oliveira e Silva. [Os dados SRTM foram cortesia do U.S. Geological Survey.]

\section{Referências}

Amador E.S. 1988. Geologia e Geomorfologia da planície costeira da Praia do Sul - Ilha Grande - uma contribuição à elaboração do Plano Diretor da Reserva Biológica. Anuário do Instituto de Geociências da UFRJ, 11:35-58.

Angulo R.J., Lessa G.C. 1997. The Brazilian sea-level curves: a critical review with emphasis on the curves from Paranaguá and Cananéia regions. Marine Geology, 140:141-166.

Angulo R.J., Lessa G.C., Souza M.C. 2006. A critical review of mid to late Holocene sea-level fluctuations on the eastern Brazilian coastline. Quaternary Science Reviews, 25:486-506.

Angulo R.J., Souza M.C. 2014. Revisão conceitual de indicadores costeiros de paleoníveis marinhos quaternários no Brasil. Quaternary and Environmental Geosciences, 05(2):1-32.

Anjos R.M., Macario K.D., Lima T.A., Veiga R., Carvalho C., Fernandes P.J.F., Vezzone M., Bastos J. 2010. Correlations between radiometric analysis of Quaternary deposits and the chronology of prehistoric settlements from the southeastern Brazilian coast. Journal of Environmental Radioactivity, 101:75-81.

Bouchet P., Taylor J. 2015. Phacoides pectinatus (Gmelin, 1791). In: MolluscaBase (2015). Disponível em: http://www.marinespecies. org/aphia.php? $\mathrm{p}=$ taxdetails\&id $=420800$. Acessado em 25 de novembro de 2016.

Blott S.J., Pye K. 2001. Gradistat: a grain size distribution and statistics package for the analysis of unconsolidated sediments. Earth Surf. Process. Landforms, 26:1237-1248.

Blott S.J., Pye K. 2008. Particle shape: a review and new methods of characterization and classification. Sedimentology, 55:31-63.

Boomer I., Frenzel P. 2011. Possible environmental \& biological controls on carapace size in Cyprideis torosa (Jones, 1850). Joannea Geol. Paläont, 11:26-27.

Dias G.T.M., Kjerfve B. 2009. Barrier and beach systems of Rio de Janeiro Coast. In: Dillenburg S.R., Hesp P.A. (eds) Geology and Geomorphology of Holocene Coastal Barriers of Brazil. Springer Publisher, NY, 225-252p. 
Eirado L.G., Heilbron M., Almeida J.C.H. 2006. Os terrenos tectônicos da Faixa Ribeira na Serra da Bocaina e na Baía da Ilha Grande, Sudeste do Brasil. Revista Brasileira de Geociências, 36(3):426-436.

Emery K.O. 1961. A Simple Method of Measuring Beach Profiles. Limnology and Oceanography, 6:90-93.

Folk R.L., Ward W.C. 1957. Brazos River Bar: A Study in the Significance of Grain Size Parameters. Journal of Sedimentary Petrology, 27:3-26.

Hesp P. 2002. A gênese de cristas de praias e dunas frontais. Mercator - Revista de Geografia da UFC, 2:119-125

Lima T.A., Macario K.D., Anjos R.M., Gomes P.R.S., Coimbra M.M., Elmore D. 2004. The earliest shellmounds of the centralsouth Brazilian coast. Nuclear Instruments and Methods in Physics Research, B 223-224:691-4.

Lisiecki L.E., Raymo M.E. 2005. A Pliocene-Pleistocene stack of 57 globally distributed benthic $\delta^{18} \mathrm{O}$ records. Paleoceanography, 20, PA1003, doi:10.1029/2004PA001071.

Macario K.D. 2003. Preparação de amostras de radiocarbono e aplicações de AMS em arqueologia e geologia marinha. Tese de Doutorado. Pós-Graduação em Física, Departamento de Física, Universidade Federal Fluminense, 138p.

Martin L., Mörner N. A., Flexor J.M., Suguio K. 1986. Fundamentos e reconstruções de antigos níveis marinhos do Quaternário. Boletim de Geociências da Universidade de São Paulo, 4:1-161.

Martin L., Suguio K., Flexor J.M. 1987. Flutuações do nível relativo do mar no Quaternário e seu papel na sedimentação costeira: Exemplos brasileiros. In: Simpósio de Ecossistemas da Costa Sul Sudeste Brasileira, 1:40-61.

Meyers P.A. 1997. Organic geochemical proxies of paleoceanographic, paleolimnologic, and paleoclimatic processes. Organic Geochemistry, 27:213-250.

Meyers P.A., Ishiwatari R. 1993. Lacustrine organic geochemistry - an overview of indicators of organic matter sources and diagenesis in lake sediments. Organic Geochemistry, 20:867-900.

Muehe D. 1998. Estado morfodinâmico praial no instante da observação: uma alternativa de identificação. Revista Brasileira de Oceanografia, 46(2):157-169.

Rabineau M., Berné S., Aslanian D., Olivet J.L., Joseph P., Guillocheau F., Bourillet JF., Ledrezen E., Granjeon D. 2006. Paleo sea levels reconsidered from direct observation of paleoshoreline position during Glacial Maxima (for the last 500,000 yr). Earth and Planetary Science Letters, 252:119-137.

Reimer P.J., Bard E., Bayliss A., Beck J.W., Blackwell P.G., Bronk Ramsey C., Buck C.E., Cheng H., Edwards R.L., Friedrich M., Grootes P.M., Guilderson T.P., Haflidason H., Hajdas I., Hatté C., Heaton T.J., Hogg A.G., Hughen K.A., Kaiser K.F., Kromer B., Manning S.W., Niu M., Reimer R.W., Richards D.A., Scott E.M., Southon J.R., Turney C.S.M., van der Plicht J. 2013. IntCal13 and MARINE13 radiocarbon age calibration curves 0-50000 years cal AP. Radiocarbon, 55(4):1869-1887.
Rocha T.B, Fernandez G.B., Peixoto M.N.O., Rodrigues A. 2013. Arquitetura Deposicional e Datação Absoluta das Cristas de Praia Pleistocênicas no Complexo Deltaico do Paraíba Do Sul (RJ). Brazilian Journal of Geology, 43(4):711-724.

Saito Y., Nishimura A., Matsumoto E. 1989. Transgressive sand sheet covering the shelf and upper slope of Sendai, Northeast Japan. Marine Geology, 89:249-258.

Salgado C.M., Peixoto M.N.O., Moura J.R.S. 2007. Caracterização espaço-temporal da chuva como subsídio à análise de episódios de enchentes no município de Angra dos Reis, RJ. Geosul, 22:7-26.

Salgado C.M., Vasquez N.D. 2009. Clima. In: Bastos M.P., Callado C.H. (eds) O ambiente da Ilha Grande. Universidade do Estado do Rio de Janeiro, Rio de Janeiro, 7-20p.

Silva A.L.C., Silva M.A.M., Santos C.L., Ribeiro G.P., Santos R.A., Vasconcellos S.C. 2008. Retrogradação da barreira arenosa e formação de leques de arrombamento na praia de Itaipuaçu (oeste de Maricá, RJ). Revista Brasileira de Geomorfologia, 9(2):75-82.

Stein R. 1991. Accumulation of organic carbon in marine sediments. Results from the Deep Sea Drilling Project/Ocean Drilling Program. Lecture Notes in Earth Sciences, vol. 34. SpringerVerlag, Berlin, 217p.

Stuiver M., Reimer P.J. 1993. Extended 14C database and revised CALIB radiocarbon calibration program. Radiocarbon, 35:215230 .

Suguio K., Martin L., Bittencourt A.C.S.P., Dominguez J.M.L., Flexor J.M. 1985. Flutuações do nível relativo do mar durante o Quaternário Superior ao longo do litoral Brasileiro e suas implicações na sedimentação costeira. Revista Brasileira de Geociências, 15:273-286.

Tenório M.C. 2000. Os fabricantes de machado da Ilha Grande. In: Tenório M.C. (ed) Pré-história da Terra Brasilis. EDUFRJ, Rio de Janeiro, 233-246p

Tenório M.C. 2003. O lugar dos aventureiros: identidade, dinâmica de ocupação e sistemas de trocas no litoral do Rio de Janeiro há 3.500 anos antes do presente. Tese de Doutorado. Pós-Graduação em História, Pontifícia Universidade Católica do Rio Grande do Sul, 600p.

Tenório M.C. 2006. Povoamento pré-histórico da Ilha Grande. In: Prado R.M. (ed). Ilha Grande: do sambaqui ao Turismo. Garamond/EDUERJ, Rio de Janeiro, 19-37p.

Tenório M.C., Pinto D.C, Afonso M.C. 2008. Dinâmica de ocupação, contatos e trocas do Rio de Janeiro no período de 4.000 a 2.000 anos antes do presente. Arquivos do Museu Nacional, 66(2):311321.

Ybert J.P., Bissa W.M., Catharino E.L., Kutner M. 2003. Environmental and sea-level variations on the southeastern Brasilian coast during the Late Holocene with comments on prehistoric human occupation. Palaeogeography, Palaeoclimatology, Palaeoecology, 189:11-24 